\title{
101
}

\section{Preservice teacher education in Information Technology: a critical perspective}

\author{
Martyn Wild \\ Ron Oliver \\ Edith Cowan University \\ Churchlands Campus \\ Western Australia
}

\begin{abstract}
This paper attempts to rationalize what is currently wrong with Information Technology (IT) programs in preservice education by examining the associated pedagogy, the content of programs and the evaluation of those programs. The paper argues not for an increase in the amount of time given to educating student teachers in IT nor for simply making changes solely to content or pedagogy. Rather the suggestion is that we need to reconceptualize the nature of the experience student teachers gain while on teaching practice. And to use this period of teaching practice as a vehicle to help build student teachers' understanding of IT use as part of their growth from novice towards expert teaching status. One strategy is presented to this end.
\end{abstract}

Main conference themes: teacher education, information technology

Educational areas: higher education

Study topics: computer literacy

Secondary keywords: curriculum development, innovation, pedagogy, teaching methods 


\section{INTRODUCTION}

At universities in Australia, the United Kingdom and elsewhere teacher educators for Information Technology (IT) greet at every new intake large groups of aspiring and enthusiastic student, make flirtatious promises of what computers and more specifically computer education has to offer them both personally and professionally, and then over a period of some two to three years witness the rapid decline of student interest followed by a very poor uptake in classroom computer use as these new teachers embark on their careers. Whether in the United Kingdom (UK), in Australia, in the United States or in France their common perception is that their training at preservice level fails to prepare them to use computer related technologies in the classroom [1, $2,3]$.

This paper will provide a critical assessment of the nature and effectiveness of preservice programs in IT and make suggestions for their improvement.

\section{The nature of IT in preservice education programs}

The use of IT in preservice education tends to mirror what occurs in the name of IT in school education [4]. Usually the formal programs use instructional models in which various IT skills explicitly are prime learning objectives. In universities computing is often also recognizable as a subject with timeslots, laboratories, subject experts and assessments. In fact, computing at school and computing at university have proved to be very similar-in pedagogy, in resource structures and in content. The implications of this are far-reaching as Collis points out: recent surveys conducted in the UK, in Europe, the United States, Canada and elsewhere all reveal that currently the typical student teacher gains preservice IT education in a separate (rather than integrated) course or program; and that such courses are characterized by a technical or computer skills orientation [5].

Alongside recent changes in school based IT in the UK and Australia because of changes in curriculum many universities have developed more fluid IT programs. Currently programs in preservice education range from discrete courses to total permeation with the technology integrated into the subject specific and general education of students. Various views have been offered on the relative merits and because there are pros and cons for each approach, many institutions adopt a mixture of both [6].

With the expectation that the future of preservice education lies in a much closer partnership between schools and universities [6], there will be fewer opportunities for discrete IT courses and much more emphasis will be placed on models of permeation. However, the emerging partnership between schools 
and universities is likely to face considerable difficulties with implications for the preparation of student teachers in IT [6].

\section{Measures of effectiveness}

The degree of preparedness of students for school based IT is traditionally measured in terms of knowledge, skill and attitudes regarding computers, for example:

For students to take advantage of the computers they find at their disposal ... they need to have some knowledge of the machine ... possess experience and skill in the use of various computers applications such as word processors and databases ... It is also desirable for students to have a balanced attitude towards computers ... [7, pp. 161-162].

Wilson goes onto describe 'a typical knowledge/skills list' desirable for student teachers to possess [7]. In line with this the effectiveness of IT programs in preservice education is typically described in terms of actual or perceived cognitive outcomes, as well as changes in attitudes and confidence.

Many studies have sought to determine the effectiveness of IT programs in teacher education [8], [9], [10], [11], 12]. Using localized and internal measures most IT programs are reported as being effective-that is, assessed in terms of changes in skills, knowledge and/or attitudes these programs are almost invariably successful.

However, were the same programs to be assessed according to their influence on the uptake of IT use by student teachers and beginning teachers in teaching practice, then they might fare less well. Indeed, if the evaluation studies conducted by Wild and Oliver are taken as indicative of more general trends, it is likely that many IT programs would be found to be largely ineffective. More emphasis on the responsibilities of schools is not necessarily going to improve this situation-it may simply serve to widen the gap between IT use of a student teacher at university and IT use during school placements.

\section{Determinants of IT use}

Many and varied factors are at play as determinants of IT use of student teachers and newly qualified teachers in classrooms. Research findings to date are wide ranging and would for example suggest that:

- at the level of the individual, attitudes, experience and student knowledge are significant [7];

- at the system level, opportunity, access to resources and number of resources are important [8]; 
- at the program level, type and duration of the program and particular teaching strategies can be identified as having some impact.

In addition a small range of specific factors can be identified which have a significant impact on the level and type of IT use, including:

- the type of roles played by supervising teachers;

- the level of knowledge of teaching methodologies using IT;

- the level of extrinsic motivation provided for student teachers to use IT.

Importantly, all these factors are dynamic, some declining in significance and others rising, influenced by changes and developments in preservice education as well as in schools. For example, access to hardware and software resources was at one time found to be a critical determinant, but is now regarded as much less significant. However, it is also probable that the factors are influenced by the context of use of IT.

\section{The effects and content of IT preservice programs}

The majority of IT programs currently offered is simplistic and unenlightened. In Byrum and Cashman's words: "the focus of training usually centres on the mechanics of running the computer and using basic tools and applications rather than integration into the curriculum".

There is a number of indications that the type of content might well influence the amount of IT use as well as the type of use. For example, research of McEneaney, et al., shows that student teachers' experiences on preservice IT programs do not lead to positive computer attitudes. Given the importance of attitude as a determinant of classroom IT use, this hardly bodes well. This finding might well be a reflection on the content of preservice IT programs.

In another case Oliver found significant differences in the level of computer uptake among beginning teachers when the content of their IT preservice courses was taken as the independent variable. Beginning teachers exposed to IT instruction which addressed teaching methodologies, were found to make significantly more use of computers in their teaching than others who had experienced preservice programs which sought to develop personal IT skills. Furthermore, in a study by Mellar and Jackson student teachers were asked to indicate their training priorities in relative importance; the results revealed that the vast majority of students listed the item "the way computers can be used in teaching", as their first priority. Clearly students here were concerned to be instructed in the educational purposes and teaching methodologies of IT use, rather than in IT skills. 
Although Dunn and Ridgway were able to demonstrate increased use of IT by students on school placements over time, they were concerned that much of this usage was of poor quality and that the students, while aware of the need to use IT in the classroom, had only restricted reasons as to why IT was important. In light of their research they concluded that preservice IT programs need to focus much more on building students' understanding of the educational purposes of software use rather than on IT skills [10].

\section{A failure of perception}

There is a number of concerns which have been raised in this paper thus far. We cannot assume that there is a qualitative difference between discreet or permeative approaches; and, more importantly, closer alignment between schools and universities will not by itself lead to improvements. There are deficiencies in many current methods of measuring the effectiveness of IT programs with evaluation often completed internally and on local measures, and based largely on changes in knowledge, skills and attitudes of program participants. However, where evaluation is completed according to more relevant and predictive measures, increases in the amount of IT use does not necessarily accompany effective IT use.

In the view of this we need to critically question the content of IT programs. Indeed, Mellar and Jackson, and others have done just thisalthough only because of the change in IT experiences current students have. Mellar and Jackson contend that students are increasingly bringing with them to university, the IT skills necessary to use a range of software and hardware and that there is consequently less need for "basic level introductions to IT"; they also suggest that "it is becoming more and more important for IT courses to be open and differentiated and to introduce students to the wide range of IT resources available to them". This in itself implies that we should simply provide courses to teach students different skills-for example, how to use a scanner or authoring software, rather than a word processor. The importance of providing for understanding of IT use is ignored. Collis provides a thoughtful comment in this context:

"According to the IEA 1991 survey, the categories 'Applications of Computers' and 'Problem Analysis and Programming' are the two major topic categories being dealt with in inservice teacher training from an international perspective. Word processing as an application of computers tends to be the most common component of teacher education courses worldwide. There is little evidence that these emphases evolved through any overall examination of teacher needs and how these can be most effectively met in teacher education programs" [5]. 


\section{A new perspective}

To enhance preservice IT programs we need to pay much more attention to overall development over time and particularly to the process of acquiring teaching expertise. Within this context we need to provide IT experiences which seek to facilitate student understanding of IT use. From a constructivist stance this can only be provided if students construct their own meaning, relevance and purpose. Evaluation of preservice IT programs should be based on relevant and predictive measures such as quality and amount of use of IT.

The remaining section of this paper outlines a strategy to improve IT in preservice education embedded in a fresh perspective recognizing greater future collaboration between schools and universities in preparing student teachers.

\section{Moving from novice to expert}

Student teachers will develop much of their teaching expertise only after they have graduated and begun teaching. It is therefore not necessarily desirable nor realistic to expect new graduates in education to be able to make use of IT in diverse and informed ways. However, a foundation for student teachers to build on should be provided. Much of this foundation has to be built during students' experiences on school placement (teaching practice). During these experiences student teachers move from novice to expert status.

Glaser describes what is understood to be expert knowledge and how this differs from that of novices-however, Glaser and other instructional psychologists are not able to tell us how novices become experts, only how the two differ. However work of Marton and Ramsden using phenomenography as a methodology shows that the key to understanding these processes lies in the interactions between teacher and student. To both understand and influence the novice-expert transition through teaching-learning strategy we must place the question of how teacher and student should interact central in our approach. We have to provide a strategy for supporting student teachers in building expertise in using IT in learning based on teacher-student cooperation and interaction.

\section{Reconceptualizing the student teacher IT experience}

Teaching practice is considered by students to be one of the most important components of their preservice program. It is also recognized to be one of the most problematic: the effectiveness of commonly applied teaching practice programs has in the past been seriously questioned. Essentially, there are two particular problems. The first is the difficulties student teachers experience in matching theory to practice-that is, in applying what they have learnt about teaching in university classes to their practice of teaching. The second problem concerns the tendency of student teachers to follow familiar or immediately 
accessible teaching practices - that is, practices which go back to when they themselves were learners at school or which have been directly derived from their supervising teachers' practices:

Cooperating teachers usually exert much more influence on trainee teachers than the academic institution. As many teachers use traditional routines, their influence reinforces the perpetuation of these routines and discourages new initiatives on the part of novice teachers.

To change this situation we need to do more than what Dunn and Ridgway suggest, that is "to improve the confidence and expertise (in IT) of the tutors with whom students work, particularly in school". We need to fundamentally reconceptualize the role of the tutors so that they may be better able to bridge the gap between theory and the reality of the classroom-so that student teachers may better understand the place and use of IT in the classroom. It is not enough to simply increase the amount of practice in or observation of IT use, since students are severely restricted in what they can learn from either observing practice or experiencing practice-novices have only limited interpretative experience.

Student teachers need a mechanism to allow them to gain a more experienced perspective on the use of IT in the classroom - to see their practice situations from the interpretative frame of a more experienced and expert tutor. One way of providing this mechanism is through a reflective workshop in which an experienced tutor guides the student teacher in the reflection process supplying interpretative frames. Such reflection would be discursive, considering alternative or theoretical ideas in the context of students' practices. Indeed, Ziv, et al., have developed this approach and found it to improve teaching performance in general terms. Such an approach is also in line with more recent views which emphasize the pivotal role of reframing experiences in the process of learning from reflection-reframing mediates between theories and practice and facilitates the construction of meaning, relevance and purpose for those engaged in reflection.

\section{CONCLUSION}

This paper has sought to rationalize what is currently wrong with IT programs in preservice education by examining the associated pedagogy, the content of programs and the evaluation of those programs. The paper argues not for an increase in the amount of time given to educating student teachers in IT nor simply in making changes solely to content or pedagogy. Rather, the suggestion is that we need to reconceptualize the experiences student teachers gain while on teaching practice and to use these as a vehicle to help build 
student teachers' understanding of IT use, as part of their growth from novice towards expert teaching status. One strategy has been presented to this end. In addition the conference presentation will also provide the results of research currently being conducted at Edith Cowan University with a small number of student teachers following the strategy of reflective workshops described.

\section{REFERENCES}

1. Sherwood, C. (1993) Australian experiences with the effective classroom integration of information technology: implications for teacher education. Journal of Information Technology for Teacher Education,. 2 (2) pp. 167-179.

2. Baron, G-L. and Bruillard, E. (1994) Information technology, informatics and pre-service teacher training. Journal of Computer Assisted Learning,. 10 (1) pp. 2-13.

3. Handler, M.G. and Marshall, D. (1992) Preparing new teachers to use technology: one set of perceptions. In, Technology and teacher education annual, Carey, R., Willis, D.A. and Willis, J. (eds) Association for Advancement of Computing in Education: Charlottesville, VA., pp. 386-388.

4. Jones, A. (1993) Preparing primary teachers for the 21st century. Australian Educational Computing,. 8, pp. 123-128.

5. Collis, B. (1994) A reflection on the relationship between technology and teacher education: synergy or separate entities? Journal of Information Technology for Teacher Education,. 3 (1) pp. 7-25.

6. Robinson, B. (1993) The English national curriculum and the information technology curriculum for teacher education. Journal of Technology and Teacher Education,. 1 (1) pp. 73-80.

7. Wilson, B. (1990) The preparedness of teacher trainees for computer utilisation: the Australian and British experiences. Journal of Education for Teaching, 16 (2) pp. 161-171.

8. Wild, M. (1991) The nature of information technology in teacher education: Towards effective practice. University of Exeter. 
9. Dunn, S. and Ridgway, J. (1991) Naked into the world: IT experiences on a final primary school teaching practice-a second survey. Journal of Computer Assisted Learning, 7 (4) pp. 229-240.

10. Dunn, S. and Ridgway, J. (1991) Computer use during primary school teaching practice: a survey. Journal of Computer Assisted Learning, 7 (1) pp. 7-17.

11. Downes, T. (1993) Student-teachers' experiences in using computers during teaching practice. Journal of Computer Assisted Learning, 9 (1) pp. 1733.

12. Monaghan, J. (1993) IT in mathematics initial teacher training-factors influencing school experience. Journal of Computer Assisted Learning,. 9 (2) pp. 149-160. 